\title{
INGRESOS LABORALES Y TIEMPOS EN EL TRABAJO EN ANTIOQUIA Y EL ÁREA METROPOLITANA DEL VALLE DE ABURRÁ 2012-2014*
}

\author{
Recibido: 04 de febrero de 2016 • Aprobado: 25 de abril de 2016
}

Jorge Coronel López ${ }^{* *}$

\section{RESUMEN}

El propósito de este artículo es analizar los indicadores relacionados con ingresos laborales y tiempos en el trabajo bajo la propuesta metodológica de la Organización Internacional del Trabajo en su programa de trabajo decente. Los datos fueron obtenidos de la Gran Encuesta Integrada de Hogares del Departamento Administrativo Nacional de Estadística para el período 2012-2014. La medición se realiza tanto para el departamento de Antioquia como para el Área Metropolitana del Valle de Aburrá. Los resultados deben ser entendidos como una línea de base y se evidencia que los ingresos laborales no le permiten a un grupo de personas ocupadas superar la línea de pobreza, mientras que una parte de los ocupados labora más del tiempo permitido.

\section{PALABRAS CLAVE}

Ingresos laborales, mercado de trabajo regional, subempleo, salarios por hora, salarios bajos.

\section{CLASIFICACIÓN JEL}

E24, R23, J31

\section{CONTENIDO}

Introducción, 1. Contexto económico; 2. Descripción metodológica; 3. Resultados; 4. Conclusiones y recomendaciones; Bibliografía; Anexo.

* Este artículo es producto del proyecto de investigación titulado Medición y análisis de las condiciones de trabajo decente en Medellín y el Valle de Aburrá, realizado en el año 2015, entre el Programa de las Naciones Unidas para el Desarrollo y la Fundación Universitaria Católica del Norte, en calidad de entidad coordinadora del Observatorio del Mercado de Trabajo de Antioquia (ORMET). Proyecto financiado por el Ministerio de Trabajo y contó con el apoyo de la Alcaldía de Medellín, a través de la Secretaría de Desarrollo Económico.

** Economista Industrial, Universidad de Medellín, Medellín, Colombia. Especialista en Finanzas Públicas, Escuela Superior de Administración Pública (ESAP), Medellín, Colombia. Magister en Economía, Universidad Nacional de Colombia, Medellín, Colombia. Profesor tiempo completo, Coordinador de la Maestría en Gobierno y Miembro del grupo de investigación en Economía Aplicada, Facultad de Ciencias Económicas y Administrativas, Universidad de Medellín, Medellín, Colombia. Dirección: Carrera 87 \#30-65 Barrio Belén Los Alpes, oficina 12-104, Universidad de Medellín, Medellín, Colombia. Correo electrónico: jecoronel@udem.edu.co. 


\section{LABOR INCOMES AND WORKING TIMES IN ANTIOQUIA AND THE METROPOLITAN AREA OF THE ABURRA VALLEY 2012-2014 ABSTRACT}

The purpose of this article is to analyze the indicators related with labor incomes and working times under the International Labor Organization methodological proposal, within their decent labor program. The data was obtained from the Great Household Integrated Survey done by the National Statistics Administrative Department corresponding to 2012-2014. The measurement was done both for Antioquia as well as for the municipalities belonging to the Metropolitan Area of the Aburra Valley. The results must be understood as a base line and these show that labor income is not allowing a group of working individuals to step outside the poverty line. It also shows that part of this population works more hours than permitted.

\section{KEY WORDS}

Labor income, Labor Regional Market, Underemployment, Wages per hour, low wages.

\section{JEL CLASSIFICATION}

E24, R23, I31

\section{CONTENT}

Introduction, 1. Economic context; 2. Methodological description; 3. Results; 4. Conclusions and recomendations, Bibliography; Attachments.

\section{INGRESSOS LABORAIS E TEMPOS NO TRABALHO EM ANTIOQUIA E NA ÁREA METROPOLITANA DO VALE DE ABURRÁ 2012-2014}

\section{RESUMO}

O propósito deste artigo é analisar os indicadores relacionados com ingressos laborais e tempos no trabalho sob a proposta metodológica da Organização Internacional do Trabalho, dentro de seu programa de trabalho decente. Os dados foram obtidos da Grande Enquete Integrada de Lares do Departamento Administrativo Nacional de Estadística correspondentes aos anos 2012-2014. A medição se realiza, tanto para o Departamento de Antioquia, como para a Área Metropolitana do Vale de Aburrá. Os resultados devem ser entendidos como uma linha de base e se evidência que os ingressos laborais não lhes permitem a um grupo de pessoas ocupadas superar a linha de pobreza, enquanto que uma parte dos ocupados trabalha mais do tempo permitido.

\section{PALAVRAS CHAVE}

Ingressos laborais, Mercado Regional do Trabalho, Subemprego, Salários por hora, Salários baixos.

\section{CLASSIFICAÇÃO JEL}

E24, R23, I31

\section{CONTEÚDO}

Introdução, 1. Contexto económico; 2. Descrição metodológica; 3. Resultados; 4. Conclusões e recomendações; Bibliografia; Anexos. 


\section{INTRODUCCIÓN}

Los cambios en los modelos de desarrollo de los países y las nuevas formas de producción han modificado, tanto las actividades económicas, como las relaciones laborales, poniendo en riesgo la estabilidad de los empleos y la calidad de vida de los trabajadores. Estas situaciones, entre otras, fueron motivo suficiente para que hacia finales de la década de los noventa la Organización Internacional del Trabajo -OIT- instara a una reflexión mundial sobre la importancia de pensar en el trabajo decente como una forma de enfrentar la creciente desigualdad, la inestabilidad económica, la desprotección laboral, las condiciones laborales degradantes y los modelos inequitativos de distribución de la riqueza. En este sentido lo señaló Somavia (1999, p. 5):

La política de liberalización económica ha trastocado las relaciones entre el Estado, el mundo del trabajo y el ámbito empresarial. En los logros económicos influyen hoy más las fuerzas del mercado que la mediación por conducto de actores sociales, normas legales o intervenciones del Estado. Los mercados internacionales de capital se han desconectado de los mercados de trabajo nacionales, acarreando beneficios y riesgos asimétricos para el capital y para el trabajo. Se tiene la impresión de que la economía «real» ha perdido contacto con los sistemas financieros, y viceversa.

La mayoría de países latinoamericanos, incluido Colombia, acumulan casi un cuarto de siglo de haber adoptado cambios en el modelo de desarrollo y llevaron a cabo una serie de políticas proclives a los mercados, abogando por unas libertades que han sido puestas en cuestión luego de la crisis financiera de Estados Unidos en 2008, pero que ya habían sido objetadas en la crisis de la burbuja tecnológica de 2001. Dichas políticas estuvieron acompañadas de reformas al Estado, tanto en una reducción en su tamaño, como en menor intervención en la producción. Esto hizo que el sector privado ocupara parte del espacio que tenía el sector público y desde allí se cambiaron las lógicas para producir, ofrecer y vender bienes y servicios en la economía. En esta línea afirma Somavia (1999, p. 5) que "la mundialización ha traído consigo prosperidad $y$ desigualdades, que están sometiendo a dura prueba el imperativo de una responsabilidad social colectiva". En otras palabras, estas políticas, que pretenden una mayor libertad de los mercados mediante una menor intervención directa del Estado en la producción y bajo un aparato estatal mínimo, son en buena parte la materialización de aquel modelo que la OIT ha cuestionado, tal como lo hizo manifestó Somavia (1999, p. 6):

Para la OIT, cuyo campo de actuación se sitúa en la intersección de la sociedad, la economía y las vidas de los seres humanos, tales cambios han revestido proporciones de cataclismo, pero están sentando también las bases para su misión futura. Las mismas fuerzas que transformaron el antiguo orden están engendrando nuevas exigencias y nuevas oportunidades de acción social. 
En el caso de Antioquia, se parte por reconocer que es la segunda economía que más contribuye a la producción nacional, después de Bogotá1, y es la primera en exportación cuando se analiza por departamentos. Su dinámica depende, tanto de condiciones internas, como de coyunturas externas, lo que quiere decir que existen diversas razones que inciden sobre su desempeño. Por ejemplo, una disminución de la actividad de la construcción en el país ha afectado a la economía regional; pero, la pasada crisis económica de Estados Unidos de 2008, sumada a la crisis diplomática entre Colombia y Venezuela, también tuvieron un impacto negativo sobre la economía del departamento. Esto refleja que es una economía que se encuentra interrelacionada con el mercado nacional, al mismo tiempo que participa del concierto internacional en doble vía (exportación e importación). En este sentido afirma la CCMA $(2015$, p.13) que "la demanda interna, específicamente el consumo de las familias y el gasto público, siguen soportando en gran medida el crecimiento de la economía de Antioquia, ya que las exportaciones y la inversión en sociedades registraron un comportamiento desfavorable". Los datos recientes reflejan que la actividad económica del departamento de Antioquia está concentrada en cuatro ramas, las cuales explican el $60 \%$ de la producción total del departamento.

\section{Gráfico 1. Participación porcentual de las principales ramas de actividad en el PIB del departamento de Antioquia 2000 vs. 2014.}

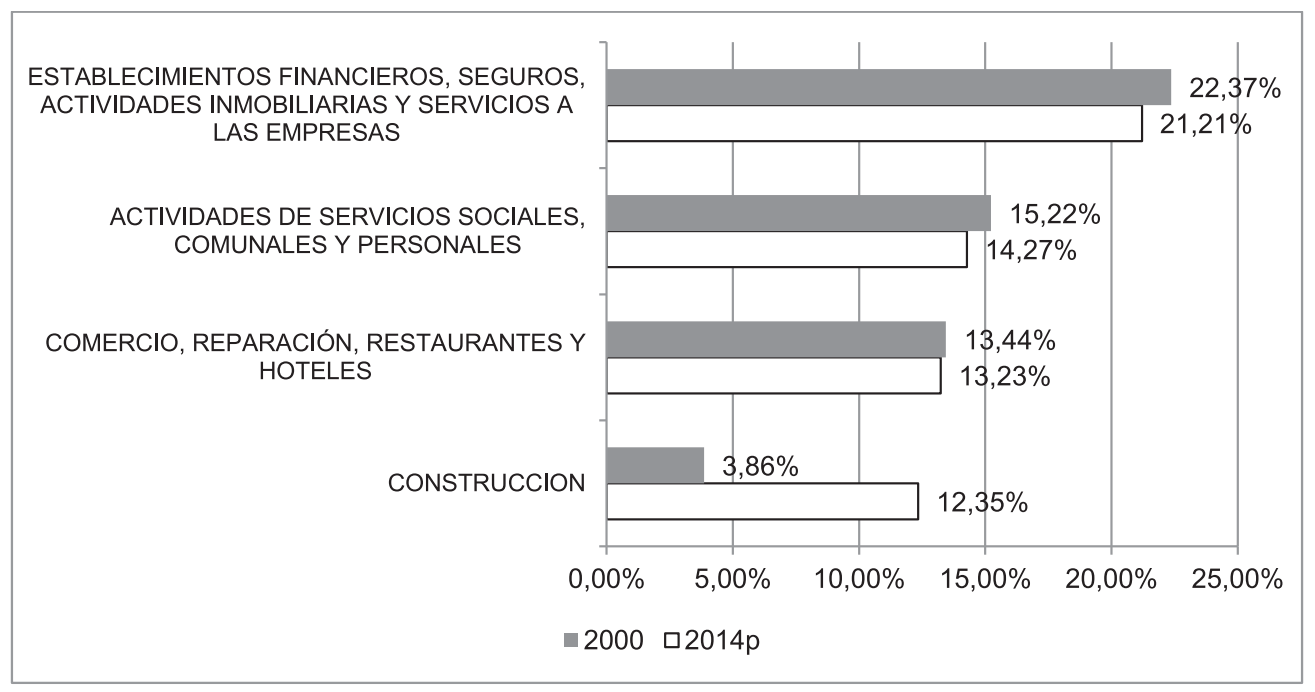

Fuente: DANE-Cuentas Nacionales Departamentales de Colombia.

De acuerdo con datos de DANE - Cuentas Nacionales Departamentales de Colombia, Bogotá participó en 2014 con 24,8 \% de la producción nacional, mientras que Antioquia con el 13,4%. 
En oposición a dichas ramas las que menos participación registran son electricidad, gas y agua y explotación de minas y canteras, lo cual ha servido como un argumento irrefutable para considerar que la economía antioqueña se ha transformado, ya que han surgido sectores que antes no sumaban dentro la estructura económica regional y que ahora son quienes la sustentan. Esta idea toma más sentido y se refuerza si se considera a Restrepo $(2011$, p. 44) cuando afirma que la industria en la década del sesenta representaba el 30 \% de la economía local, mientras que en 2004 representó el 18 \%, y concluye que este cambio obedeció "al deterioro de actividades tradicionales como los textiles, al desarrollo de nuevas industrias en otras regiones de Colombia y a las ventajas de la proximidad de los puertos o de los mercados, que hicieron que la mayoría de las nuevas empresas manufactureras se localizaran fuera del departamento".

Según los datos de 2014, las cifras son aún más desalentadoras, ya que la participación industrial fue $12 \%$, poniendo en evidencia el proceso de desindustrialización que ha soportado la economía antioqueña, e incluso, el país.

Esta transformación económica debe llamar la atención, no solo por considerar el carácter industrial que predominó a mediados del siglo XX, sino que no se debe desconocer que los orígenes de la economía antioqueña estuvieron asociados al desarrollo de la minería del oro. En consecuencia, todo este devenir de la historia económica de la región refleja que las actividades que otrora predominaron ahora han sido sustituidas por nuevas ramas de la producción, lo que ha traído consigo cambios en las condiciones de vida de las familias, cambios culturales, nuevos ordenamientos territoriales, entre otros aspectos, según Betancur, Urán y Stienen (2001, p. 97):

La dinámica de localización de la industria manufacturera del Valle de Aburrá a partir de 1960, ha transformado, con su expansión, algunos territorios más allá de sus propios límites, extendiéndose a regiones como el Oriente antioqueño... En este sentido, la reconfiguración territorial que se ha dado, ha operado más como una expansión de la tradicional Área Metropolitana del Valle de Aburrá, que como una dinámica autónoma del Oriente antioqueño.

Sin embargo, detrás de estas transformaciones en la estructura económica de la región lo que parece que ha persistido es un poder hegemónico de unas élites empresariales que siempre han participado y orientado el desarrollo productivo. Franco (2006, p. 35) plantea que algunas hipótesis arriesgadas que se han construido para intentar explicar los cambios económicos y sociales de la región tienen que ver con una ruptura en las relaciones entre la dirigencia empresarial y política, "a lo cual se le atribuye, además la 'falta' de un proyecto político y territorial vinculante, que proporcione estabilidad política y bases económicas al desarrollo de la ciudad y su entorno regional". Esta es casi la misma idea que plantea Uribe (2006) citada por Restrepo (2011, p. 37) al hablar 
sobre el modelo de la sociedad antioqueña pero dentro de un contexto colonial, en donde identifica "la existencia de un proyecto regional concebido por las élites económicas y políticas dentro de un criterio de sociedad incluyente, desde antes de la independencia, y discutido y elaborado formalmente durante el periodo 1808-1821". Comparando estas dos ideas, lo que se percibe es que las elites - dirigencia- empresarial y política concibieron un proyecto regional conjunto, tanto en la Colonia, como en la Independencia, pero luego con el tiempo, y tras notables cambios en las formas de gobierno en el país, se produjo una ruptura que hoy debe seguir siendo estudiada.

Si se vuelve sobre la idea de la transformación de la economía antioqueña y si se asume como un hecho que ya no tiene objeción, surgen unas inquietudes que no deben ser depuestas para seguir estudiando el modelo de sociedad antioqueña y su relación con el mercado de trabajo, pues así como Uribe (2006, p. 37) considera que el modelo de sociedad concebido por los fundadores del Estado antioqueño contenía unas propuestas y unos mensajes claros, hoy convendría preguntar sobre cuál es el modelo de sociedad que se tiene o se quiere construir. Dice Uribe (2006, p. 282) que en dicho modelo de sociedad formulado por los fundadores del Estado se proponía que el trabajador, el campesino o el minero debían dedicar:

[...] todos sus esfuerzos hacia el trabajo manual con fines útiles, se preocuparán por garantizar la unidad familiar y por sancionar todos aquellos comportamientos que atenten contra el trabajo, como la vagancia, por ejemplo, y contra la familia, como la prostitución, el abandono del hogar paterno, la desobediencia doméstica, los juegos de azar, el consumo de licor, es decir, una estricta moral privada tutelada por la Iglesia católica, que contrastaba con la apertura en otros campos como el económico mercantil, donde se les ofrecía un horizonte de progreso para los más hábiles, los más capaces y los más arraigados; en esta esfera, el desafío a las leyes de Dios y de los hombres se toleraba en tanto que los resultados fuesen exitosos.

De esta manera conviene poner de relieve la situación actual de la región, en donde se confirma que la estructura económica se ha transformado, pero, con ella, también las relaciones sociales, laborales y el modelo de sociedad. En tal sentido, valdría la pena preguntar si el tipo de sociedad imperante hoy en la región ha sido producto de acuerdos o consensos de los actores o, por el contrario, ha sido la convulsión económica, los imperativos modelados desde un orden internacional y el devenir de las nuevas actividades -legales e ilegales- los que han terminado modelando el tipo de sociedad. En este sentido, Proantioquia (2013, p. 292) afirma que:

Antioquia es un departamento de contrastes. Posee una capital competitiva con una economía fuerte y relativa industrialización, una población con tasas de educación elevada e indicadores sociales positivos. Pero también una periferia con graves problemas económicos, baja productividad y competitividad, alto índice de necesidades básicas insatisfechas, presencias de economías criminales e inequidad en el acceso a la tierra, entre otros problemas. 
Según lo descrito, Franco (2006, p. 44) citando a Betancur, Urán y Stienen (2001), afirma que se acepta el estancamiento relativo del sector industrial en la ciudad y destaca que dichos autores "intentan hacer una lectura más estructural de dicha situación, buscando caracterizarla como la expresión urbano-regional de las transformaciones en el patrón de acumulación y el modo de regulación" que luego, con la llegada de la apertura económica a principios de los noventa, se produjeron unos cambios en la estructura productiva de la región que facilitaron el desarrollo de actividades como los servicios, aunque a costa del deterioro -estancamiento-industrial y del bajo sostenimiento de la agricultura, lo que hizo que la región perdiera peso relativo en el ámbito nacional.

Esta transformación económica de la ciudad produjo cambios en el mundo laboral, sobre todo en la gestión del trabajo, y redujo y casi que desapareció la organización obrera, con lo que impidió el diálogo para la negociación de las condiciones de trabajo. Esto fue posible gracias a que aprobaron reformas laborales bajo la lógica de hacer más flexibles las relaciones del mercado de trabajo. Según Puig (2011, p. 43) "la desregulación laboral, que abrió las compuertas a las formas de flexibilidad y subcontratación laborales que conocemos hoy, vino en América Latina con las aperturas económicas, unilaterales o por acuerdos comerciales y la desregulación en general de los mercados". Esta es misma idea de Betancur, Urán y Stienen (2001, p. 52) cuando afirman:

La apertura económica pone en riesgo la posibilidad de autodeterminación de las naciones, obligadas a abrir sus fronteras, sin ninguna contraprestación, más allá de inscribirse a las leyes del mercado, de ser competitivas; este riesgo se convierte en amenaza, ante la ausencia de un proyecto político nacional que lo inscriba en condiciones distintas en el escenario de competencia global. Ante estos riesgos, las ciudades buscan conectarse de manera directa al mercado internacional, vendiendo su imagen, reconvirtiendo su tradición productiva, y aún más, transformando su tejido urbano-espacial para adecuarse al concepto de mercado que exige la venta de la ciudad. Se han generado así, importantes transformaciones en el mercado de trabajo de las ciudades. Según los conceptos de Castells y otros, se empieza a hablar de la ciudad dual, en donde aparece una suerte de mercados de trabajos paralelos, no formales, que se expanden como consecuencia de las transformaciones de la anterior relación capital-trabajo.

Asimismo, las reducciones de costos mediante expulsión de trabajadores, reducción de salarios y descentralización de procesos productivos, también ayudaron en la transformación drástica, tanto de la actividad productiva, como del mundo del trabajo, lo cual fue facilitado por unas medidas de flexibilización laboral que permitieron contratos más dóciles y la explotación extensiva de la mano de obra en el sector informal de la economía, según Betancur, Urán y Stienen (2001) y Franco (2006). 
En este orden de ideas, dicha transformación económica y sus efectos en el mundo del trabajo fueron provocados, en buena parte, por la introducción de un modelo económico inspirado en unos paradigmas de libertad de mercado que son lo mismo que la OIT propone cuestionar. En tal sentido, la OIT $(1999$, p. 8) define que su finalidad primordial es:

[...] promover oportunidades para que los hombres y las mujeres puedan conseguir un trabajo decente y productivo en condiciones de libertad, equidad, seguridad y dignidad humana", al tiempo que establece que "el trabajo decente es el punto de convergencia de sus cuatro objetivos estratégicos: la promoción de los derechos fundamentales en el trabajo; el empleo; la protección social y el diálogo social".

Con ello lo que pretendía el organismo era elevar una propuesta -trabajo decente- para que los países empezaran a repensar sus modos y formas de relación en el mundo del trabajo. Esta propuesta evidentemente desde el inicio (1999) tuvo un enfoque multidimensional y como tal debe ser entendida, lo cual queda en evidencia si se revisa el énfasis que la OIT (2008, p. 13) hace a los cuatro objetivos estratégicos definidos para el Programa de Trabajo Decente: "son inseparables, están interrelacionados y se refuerzan mutuamente. La falta de promoción de cualquiera de ellos menoscaba el logro de los demás". Asimismo, Ghai (2003, p. 125) parte de esta misma premisa, pero advierte que "el problema es cómo hallar los 'medidores' que abarquen todos estos asuntos y que expresen las interrelaciones que los unen". Por lo tanto, es evidente que la pretensión de la OIT siempre ha sido tratar de vincular en un solo concepto un conjunto de hechos y situaciones que intervienen o tienen relación con el trabajo.

En tal sentido, la medición y el análisis del trabajo decente bajo esta perspectiva permiten poner de relieve la importancia que tienen las estructuras económicas y su relación con el mundo laboral, pues tal como se enunció, dichas estructuras han modelado un relacionamiento con el mundo del trabajo que es necesario comprender a la hora de acercarse a un estudio de este tipo, pues a partir de dicha modelación es como se ha gestado una serie de tensiones que inciden sobre el trabajo decente. Bajo esta perspectiva, la OIT ha diseñado un conjunto de indicadores con el fin de volver medible dicho concepto y, de esta manera, permitir la estructuración de un sistema de medición en donde se combine información ya existente con información que probablemente haya que levantar. Sin embargo, la idea del organismo internacional es que las autoridades se apropien de este sistema de información y a partir de allí definan metas. Dichos indicadores tienen la bondad de contribuir también al estudio del mercado laboral desde diversas perspectivas, lo cual se convierte en un nuevo enfoque que ofrece diferentes rutas de análisis sobre dicho mercado.

En consecuencia, el presente trabajo pretende aportar más información que permita aproximarse hacia una comprensión cualitativa y cuantitativa sobre el tra- 
bajo decente en Antioquia y el Área Metropolitana del Valle de Aburrá -AMVA-, a partir del cálculo de los indicadores relacionados con ingresos laborales y tiempos en el trabajo bajo la propuesta metodológica de la OIT. Para ello se toman como referencia los indicadores propuestos por dicha organización, y para los datos se recurre a la Gran Encuesta Integrada de Hogares -GEIH- que realiza el DANE bajo una agregación de datos anuales (2012-2014) para cada indicador.

En la primera parte se presenta el contexto económico del AMVA. Conviene aclarar que Colombia está dividida en 32 departamentos y 1101 municipios, en donde Antioquia es el segundo departamento en importancia en el país y su capital es el municipio de Medellín. Entretanto, las Áreas Metropolitanas son unidades administrativas conformadas por la unión de varios municipios, por lo tanto, el AMVA está compuesta por Medellín, Caldas, La Estrella, Sabaneta, Itagüí, Girardota, Bello, Copacabana y Barbosa. En la segunda parte se describe la metodología del trabajo y en la tercera se detallan los indicadores y los respectivos resultados. Al final se presentan las conclusiones y posteriormente se incluye un anexo con las fichas técnicas de cada indicador.

\section{CONTEXTO ECONÓMICO}

Una parte de la discusión sobre la pobreza pasa por la importancia que representa el trabajo y los consecuentes ingresos monetarios dentro de los hogares, ya que de allí es posible acceder a un bienestar propio de cada uno de sus miembros según sus características y condiciones. El trabajo remunerado -y especialmente el salario mínimo- es la principal fuente de ingresos para las familias y es un mecanismo que sirve para reducir la pobreza. Por ello es que la OIT anima a los Estados miembros a adoptar remuneraciones mínimas y recomienda que su determinación sea producto de una interlocución entre las autoridades y los actores sociales bajo un enfoque equilibrado, en donde se tomen en consideración las necesidades de los trabajadores y sus familias, entre otros factores, como la productividad, los requerimientos para el desarrollo económico y la necesidad de mantener un alto nivel de empleo, según OIT (2013a).

Esta premisa es la que justifica la medición de los ingresos de los trabajadores desde una perspectiva de pobreza, con el fin de poder luego construir programas o políticas que conduzcan siempre a mejorar sus condiciones salariales. Esta medición bajo la metodología OIT es la primera vez que se realiza en el departamento de Antioquia y en el AMVA; por lo tanto, puede ser entendida como una línea de base, al tiempo que no existe información semejante para comparar. 
Teóricamente se sostiene que los ingresos guardan relación con el crecimiento económico y que dicho crecimiento trae consigo la creación de nuevos puestos de trabajo; por lo tanto, antes de presentar los resultados es conveniente conocer la relación entre el ciclo económico y el comportamiento del desempleo en el AMVA como una manera de aproximarse al estudio de la dinámica del mercado laboral local. La evidencia empírica demuestra que entre los años 2007 y 2009 cuando la tasa de crecimiento del PIB de Medellín pasó de $8 \%$ a 3,5\%, se produjo un aumento del desempleo de $12 \%$ a $15,7 \%$, lo que se pudo haber traducido en cerca 85.000 nuevos desempleados. Esta sencilla evidencia empírica muestra una posible relación entre dichas variables, ratifica y amplía los hallazgos de López, Lotero y Arango (1992) y de López (1997), y sirve para llamar la atención en estos momentos cuando la ciudad y su área metropolitana enfrentan dificultades económicas.

Otra evidencia es que históricamente la tasa de ocupación del AMVA ha sido menor al promedio del total de las 13 áreas metropolitanas, mientras que la tasa de desempleo ha sido superior a dicho promedio, lo cual todavía se corrobora a pesar de que el desempleo ha disminuido y la ocupación ha crecido, tal como se puede apreciar en el siguiente gráfico 2.

\section{Gráfico 2. PIB de Medellín frente a Tasa de desempleo del AMVA}

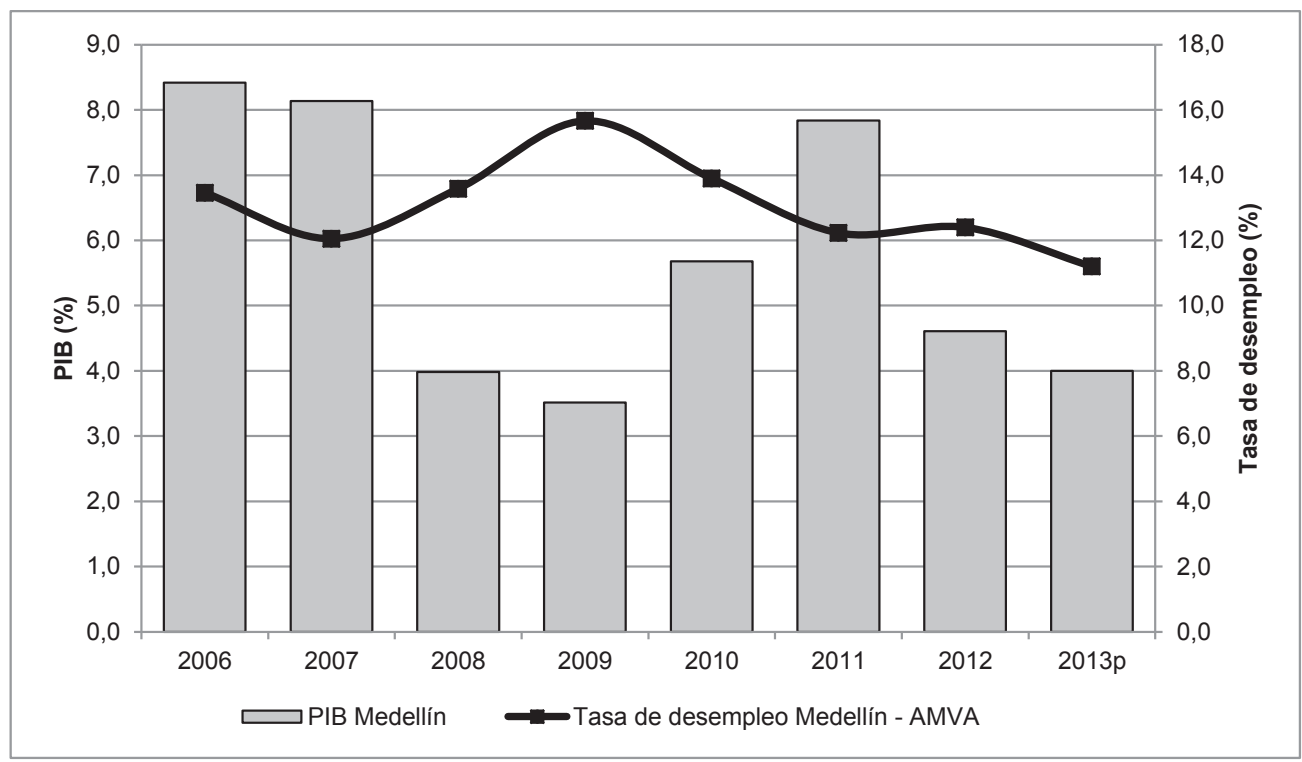

Fuente: Alcaldía de Medellín y GEIH-DANE 
Gráfico 3. Evolución del empleo-desempleo en el AMVA²

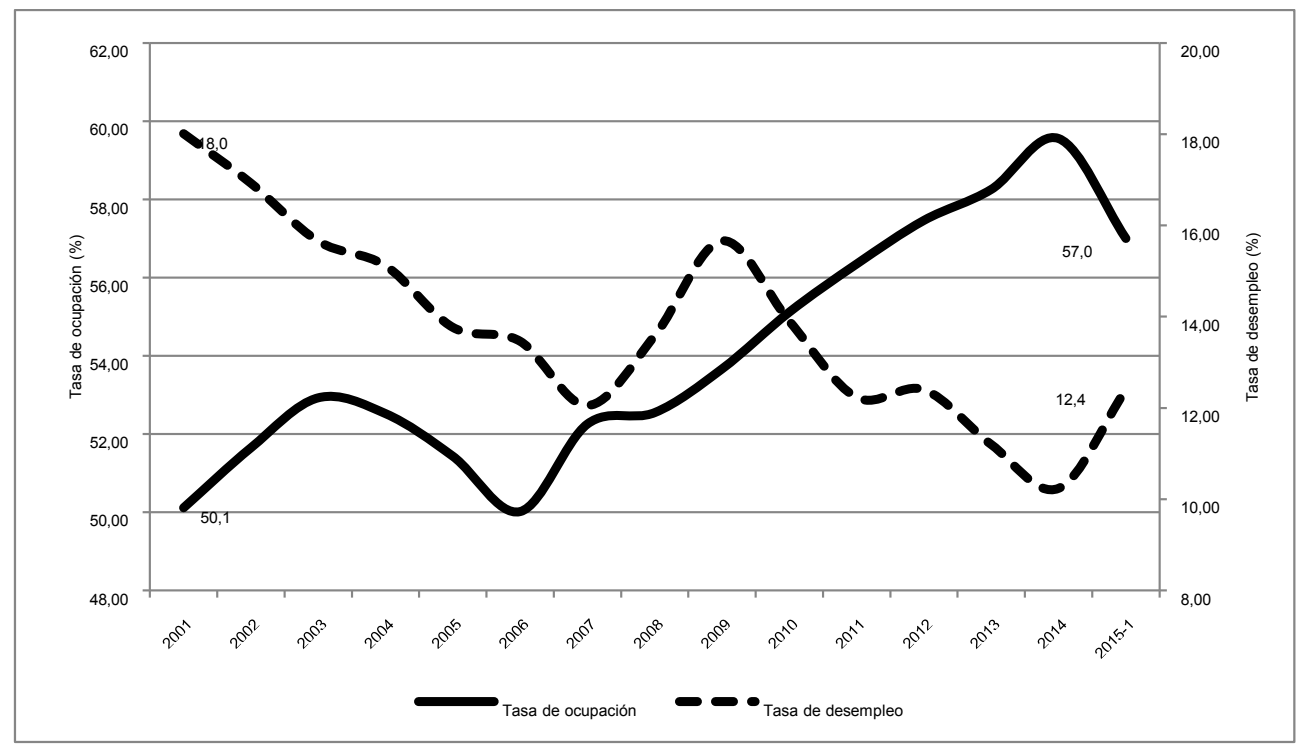

Fuente: GEIH-DANE

Algunas de las críticas que se hacen a esta relación tienen que ver con la calidad de los empleos, la sostenibilidad de los mismos y el tipo de contrato que se utiliza -término definido-. Por ejemplo, la OCDE (2016, p.18) afirma que el país enfrenta problemas estructurales en el mercado laboral, como el elevado nivel de autoempleo ( $52 \%$ de la población trabaja como independiente), los contratos a término definido (34 \% de los empleados en 2013) y la subcontratación por medio de empresas de servicios temporales ( $9 \%$ de los empleados que tenían contratos por escrito).

Conviene señalar que es normal que el mercado laboral durante el primer trimestre de cada año refleje unos ajustes derivados del ciclo económico, es decir, al pasar la temporada de diciembre se registra un aumento en el desempleo y una disminución en el empleo. No obstante, hay que tener en cuenta que en el AMVA siete (7) de cada diez (10) ocupados están concentrados en tres sectores económicos (comercio, servicios e industria manufacturera) y que dichos sectores han demostrado cierta sensibilidad frente al ciclo económico. Además, conviene recordar que en el AMVA se ha deteriorado el nivel de empleo industrial debido al proceso de desindustrialización y a la movilidad empresarial, aunque el sector relacionado con actividades inmobiliarias, empresariales y de alquiler ha aumentado el nivel de empleo y la participación en el total en dichos períodos de desaceleración económica. Asimismo, mantiene

2 Los datos para el año 2015 son los únicos que corresponden al trimestre móvil Enero-Marzo, los demás corresponden a datos anuales. 
una tendencia creciente desde 2005, creando aproximadamente 100.000 empleos desde entonces. También es importante mencionar que la construcción aporta el 7 $\%$ del empleo total y registra una tendencia creciente, tal vez producto del auge que todavía parece presentarse en el Área Metropolitana. Según Coronel $(2015$, p. 8) si continúa esta tendencia pese a la desaceleración económica que se tiene prevista en 2016, podría ayudar a amortiguar la caída del empleo, máxime cuando la ciudad avanza en megaproyectos como Parques del Río, el túnel de Oriente, entre otros.

Si se deja a un lado este contexto, los otros dos aspectos que se estudian, además de los ingresos laborales, tienen que ver con los tiempos en el trabajo y el tiempo del trabajo no remunerado frente al remunerado. El primero refleja la situación de los trabajadores en términos de los tiempos que pasan cuando desarrollan actividades laborales. La hipótesis puede ser que existe una preocupación sobre la posibilidad de que los trabajadores laboren más horas de las permitidas o que consideren que están subutilizados bajo razones de tiempo; en otras palabras, es una dimensión que ofrece información sobre la relación ocupación y tiempo laboral. Si bien en el país el tiempo en el trabajo no hace parte de la negociación de los contratos, sino que simplemente es una información que se entrega a los trabajadores en razón a un horario que deben cumplir, en ocasiones se presentan casos donde ni siquiera se respeta dicho horario. Esta información intenta poner de relieve la importancia de los acuerdos y los arreglos en el trabajo como resultado de un proceso de diálogo social, temas sobre los cuales la OIT viene enfatizando.

El segundo aspecto -tiempo del trabajo no remunerado frente al remuneradopretende contraponer las relaciones entre el trabajo y la vida familiar y personal de los trabajadores. Se hace un análisis diferenciado por sexo, ya que existe una preocupación particular sobre las mujeres, quienes pueden ejercer actividades no remuneradas como el cuidado de niños, ancianos o actividades propias del hogar. La OIT (2013, p. 83) propone medir estos tiempos que, de alguna manera, se vinculan con un área de estudio que se denomina economía del cuidado.

\section{DESCRIPCIÓN METODOLÓGICA}

La OIT (2013) definió diez dimensiones con el fin de medir el trabajo decente, y a cada una de ellas le asignó un grupo de indicadores específico. Si bien el propósito del organismo internacional era ofrecer un método de análisis para aproximarse al concepto, también se puede afirmar que dicha definición contribuye en la compresión y análisis del mercado laboral, pues va más allá de los habituales indicadores utilizados en estos estudios y genera, desde otra perspectiva, una información que podría ser un insumo valioso para el diseño de políticas laborales o de empleo. 
Para realizar la medición se toma como referencia dicha guía de indicadores propuesta por OIT (2013) y de allí se recurre a las dimensiones 2, 3 y 4 que corresponden a ingresos laborales, tiempos en el trabajo y conciliación del trabajo, la vida familiar y la vida personal, respectivamente. La información para realizar los cálculos proviene de la GEIH del DANE, y el período seleccionado para el análisis es 2012-2014, bajo la agregación de datos anuales. Los resultados fueron calculados, tanto para el departamento de Antioquia, como para el AMVA, de tal manera que se presentan resultados de cada indicador y se realiza una comparación entre el departamento de Antioquia y el AMVA, además de presentar resultados por sexo.

\section{RESULTADOS}

A continuación, se detalla cada uno de los indicadores con sus respectivos resultados, y en un anexo se presentan las fichas técnicas.

\subsection{Tasa de trabajadores pobres}

Este indicador ofrece información sobre la relación empleo-pobreza, es decir, combina datos del mercado de trabajo (ocupación) con datos de ingresos de los hogares, midiéndose así el porcentaje de trabajadores que, aunque tienen un empleo, viven en hogares identificados como pobres. Hay que aclarar que el concepto de pobreza aplicado en este indicador corresponde a que el ingreso familiar per cápita es inferior a la línea de pobreza; por lo tanto, es un concepto que se aplica a los hogares y no a los individuos. Según estas consideraciones, una reducción de este indicador significa avances en la dimensión de ingresos suficientes y productividad propuesto por la OIT; por ende, son avances hacia el trabajo decente.

Gráfico 4. Tasa de ocupados pobres

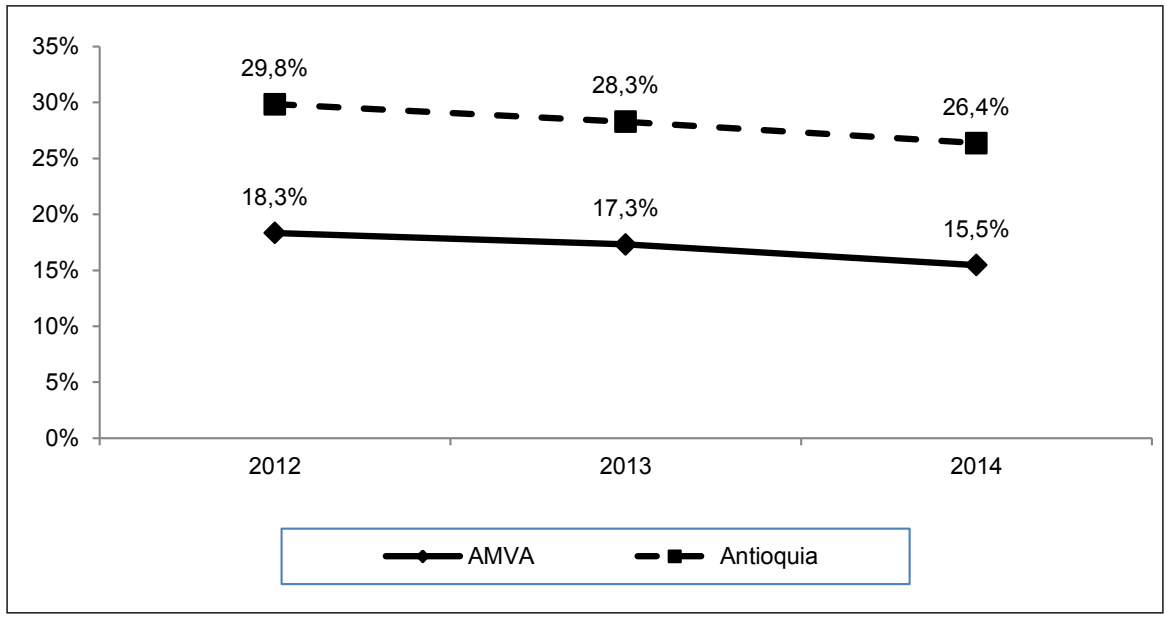

Fuente: elaboración propia con base en DANE-GEIH 
Los resultados reflejan una disminución en el indicador, tanto para el AMVA, como para el departamento, lo cual es positivo; pero una política social o laboral debería persistir sobre estrategias de redistribución del ingreso y mejoras en la productividad, con el fin de mejorar los ingresos reales de los hogares para disminuir la pobreza y mejorar el trabajo decente. Si se analizan los resultados por sexo para el AMVA, las mujeres son las que registran mayores tasas; mientras que si se analizan los datos en el ámbito departamental, son los hombres los que registran un indicador más alto.

Tabla 1. Tasa de ocupados pobres por sexo

\begin{tabular}{|c|c|c|c|c|c|c|}
\hline \multirow[b]{2}{*}{ Año } & \multicolumn{2}{|c|}{2012} & \multicolumn{2}{|c|}{2013} & \multicolumn{2}{|c|}{2014} \\
\hline & $\circ$ & & & & & \\
\hline AMVA & $17,59 \%$ & $19,23 \%$ & $16,45 \%$ & $18,33 \%$ & $14,97 \%$ & $16,05 \%$ \\
\hline Antioquia & $30,90 \%$ & $28,32 \%$ & $29,37 \%$ & $27,01 \%$ & $27,40 \%$ & $24,93 \%$ \\
\hline
\end{tabular}

Fuente: elaboración propia con base en DANE-GEIH

\subsection{Tasa de asalariados con bajos ingresos}

Este indicador complementa la lectura sobre ingresos insuficientes y productividad, ya que, sumado al indicador anterior, empieza a ofrecer pistas sobre qué tan pobres son los trabajadores, según la distribución de los salarios por hora. Se considera como un asalariado pobre aquel ocupado asalariado que devenga menos de 2/3 de la mediana del salario por hora en cada año. En tal sentido entre más alto sea el indicador significa que existe un mayor número de asalariados que reciben una baja remuneración.

Gráfico 5. Tasa de asalariados con bajos ingresos

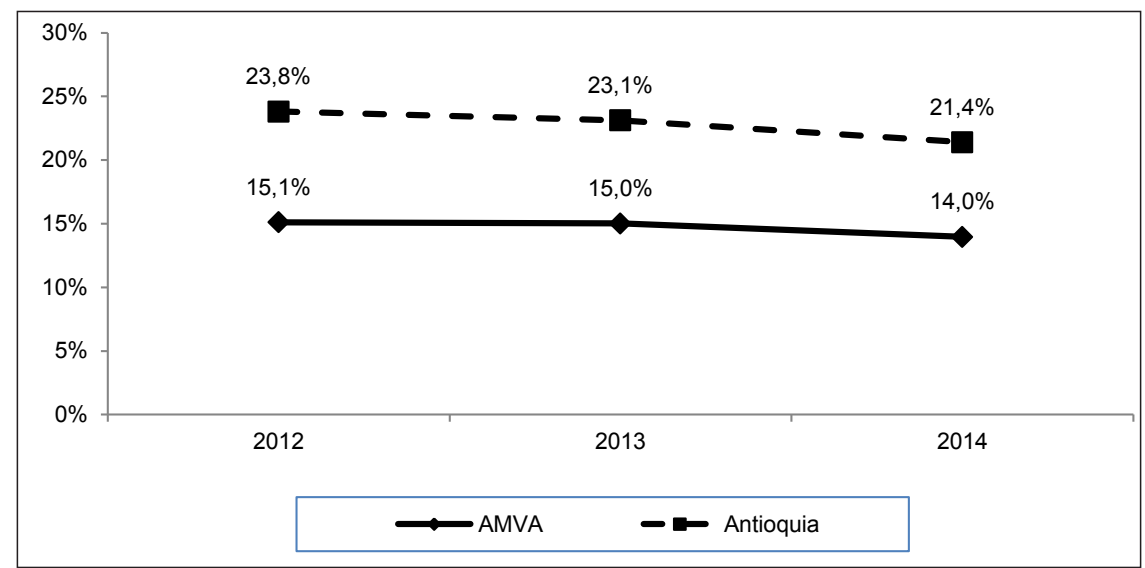

Fuente: elaboración propia con base en DANE-GEIH 
Los resultados muestran que en el AMVA dicho indicador pasa de $15,1 \%$ a $14 \%$, lo cual significa una disminución de 1,1 puntos, mientras que en el contexto departamental la mejora fue 2,4 puntos. La brecha entre el AMVA con el departamento reflejó un leve cierre.

Los resultados por género muestran que en el AMVA las mujeres siempre registran una mayor tasa que los hombres; sin embargo, debe llamar la atención que son precisamente las mujeres las que registran avances y mejoras, mientras que los hombres permanecen casi constantes (ver tabla 2). Esto es positivo y puede ayudar a pensar en la construcción de más y mejores estrategias para el trabajo decente local. Entretanto, la situación en el Departamento es diferente: allí son los hombres los que tienen una mayor tasa, y ambos mejoran en el indicador, pero las mujeres disminuyen más su indicador que los hombres.

Tabla 2. Tasa de asalariados con bajos ingresos por sexo

\begin{tabular}{|c|c|c|c|c|c|c|}
\hline \multirow[b]{2}{*}{ Año } & \multicolumn{2}{|c|}{2012} & \multicolumn{2}{|c|}{2013} & \multicolumn{2}{|c|}{2014} \\
\hline & & & & & & \\
\hline AMVA & $13,85 \%$ & $16,60 \%$ & $13,95 \%$ & $16,24 \%$ & $13,09 \%$ & $14,98 \%$ \\
\hline Antioquia & $23,87 \%$ & $23,71 \%$ & $23,97 \%$ & $21,87 \%$ & $21,78 \%$ & $20,85 \%$ \\
\hline
\end{tabular}

Fuente: elaboración propia con base en DANE-GEIH

Si se revisa este indicador según el nivel educativo, se evidencia que los asalariados que obtienen bajos ingresos son aquellos que no tienen formación o tienen educación incompleta, ya sea porque solo terminaron la primaria o la básica secundaria.

Tabla 3. Tasa de asalariados con bajos ingresos según nivel educativo

\begin{tabular}{|c|c|c|c|c|c|}
\hline Año & Ninguno & Básica Primaria & Básica Secundaria & Media & Superior \\
\hline 2012 & $36,92 \%$ & $26,49 \%$ & $27,82 \%$ & $14,65 \%$ & $6,70 \%$ \\
\hline 2013 & $32,34 \%$ & $28,76 \%$ & $26,69 \%$ & $15,15 \%$ & $6,25 \%$ \\
\hline 2014 & $44,53 \%$ & $25,59 \%$ & $26,19 \%$ & $15,20 \%$ & $5,10 \%$ \\
\hline
\end{tabular}

Fuente: elaboración propia con base en DANE-GEIH

\subsection{Ingreso laboral medio por hora}

Este indicador muestra un nivel promedio de los ingresos laborales por hora de los trabajadores que, en principio, para un nivel agregado territorial, solo produce 
una idea sobre una evolución nominal; pero desde allí se debería derivar una serie de análisis, ya sea por nivel educativo o por posición ocupacional, que es como se podría enriquecer la formulación de políticas laborales.

Conviene advertir que dentro de los ingresos se consideran los monetarios y en especie, tanto de la primera como de la segunda actividad declarada. Según los resultados, en el AMVA los ingresos laborales medios por hora han crecido en términos nominales, al pasar de $\$ 6.582$ a $\$ 7.333$, al igual que ocurre a nivel departamental, el cual ha crecido de $\$ 5.125$ a $\$ 6.594$.

\section{Gráfico 6. Ingreso laboral medio por hora}

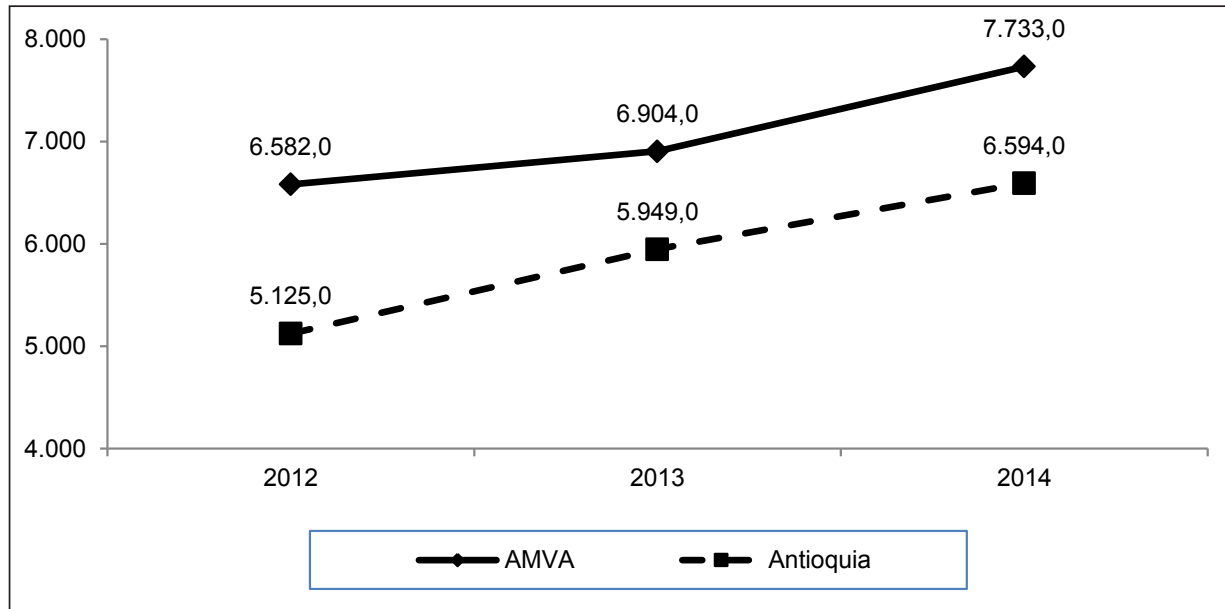

Fuente: elaboración propia con base en DANE-GEIH

Si se analiza este indicador por sexo, se comprueba que en el AMVA las mujeres tienen un ingreso medio por hora menor que los hombres; mientras que en el contexto departamental el comportamiento entre hombres y mujeres, si bien es creciente para ambos, las mujeres en 2013 estuvieron por encima de los hombres.

Tabla 4. Tasa de ingresos medios por hora según sexo

\begin{tabular}{|c|c|c|c|c|c|c|}
\hline \multirow{2}{*}{ Año } & \multicolumn{2}{|c|}{2012} & \multicolumn{2}{c|}{2013} & \multicolumn{2}{c|}{2014} \\
\cline { 2 - 7 } & n & n & n & n & n & in \\
\hline AMVA & 6693 & 6453 & 7105 & 6673 & 8164 & 7237 \\
\hline Antioquia & 5135 & 5111 & 5872 & 6061 & 6673 & 6480 \\
\hline
\end{tabular}

Fuente: elaboración propia con base en DANE-GEIH 
Desagregados estos datos según el nivel educativo y para los mismos años, se encontró que aquellos trabajadores en el AMVA que poseen Educación Superior pasaron en términos nominales de $\$ 10.121$ a $\$ 11.967$, mientras los que no tienen ninguna formación son los que registran los menores ingresos por hora y pasaron de $\$ 3.296$ a $\$ 3.661$.

Tabla 5. Tasa de ingresos medios por hora según nivel educativo

\begin{tabular}{cccccc}
\hline Año & Ninguno & Básica Primaria & $\begin{array}{c}\text { Básica } \\
\text { Secundaria }\end{array}$ & Media & Superior \\
2012 & 3296 & 3755 & 3772 & 4532 & 10.121 \\
2013 & 3647 & 3925 & 4368 & 4644 & 10.375 \\
2014 & 3661 & 4116 & 4192 & 4777 & 11.967 \\
\hline
\end{tabular}

Fuente: elaboración propia con base en DANE-GEIH

\subsection{Salario promedio real}

Este indicador se incluye en la medición pero debe ser interpretado con la debida limitación que representa, dado que la información utilizada -GEIH del DANEcaptura ingresos brutos, más no netos; por lo tanto, se restringe el análisis sobre capacidad de compra de los hogares. En tal sentido, su resultado solo refleja la evolución de los salarios promedio reales en el tiempo, valorados a precios de 2008.

\section{Gráfico 7. Salario promedio real}

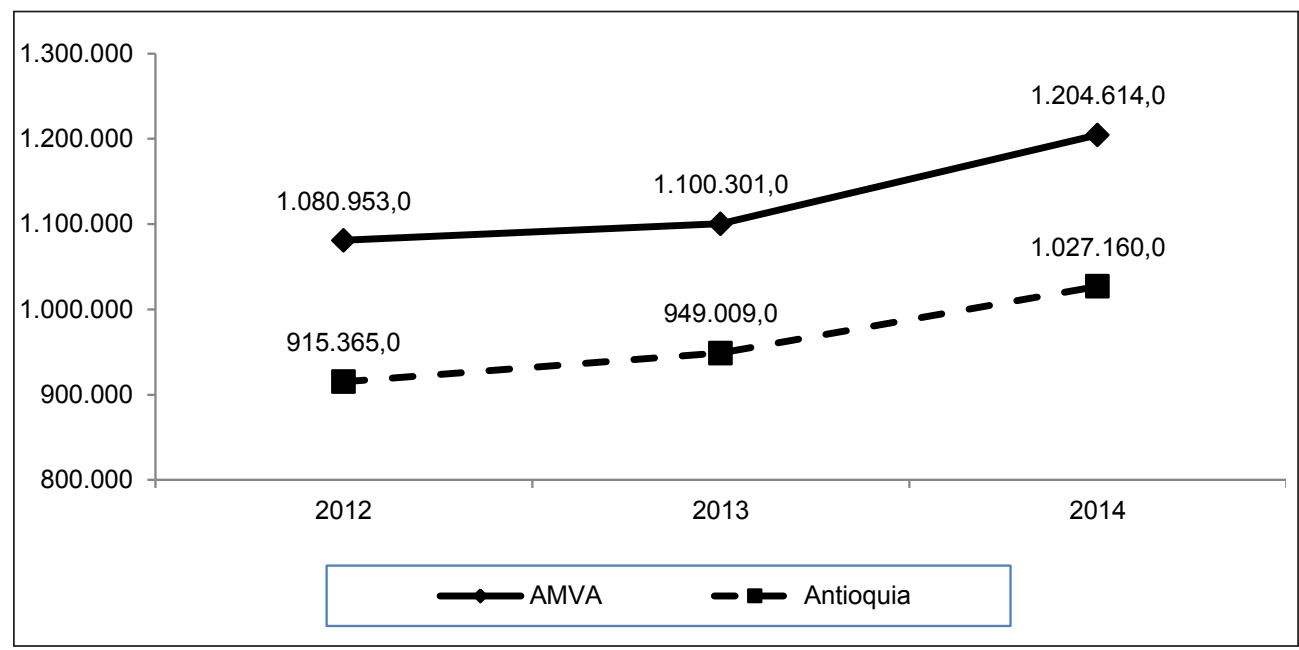

Fuente: elaboración propia con base en DANE-GEIH 


\subsection{Tasa de asalariados con capacitación reciente}

La idea de capacitarse en el trabajo o mientras se desarrolla una actividad laboral se fundamenta en premisas de mayor productividad, en el aumento y la actualización de conocimientos y en la posibilidad de ajustar las habilidades de los trabajadores a la espera de que ello repercuta, tanto en las empresas, como en el trabajador, al provocar más cualificación según el enfoque de la capacitación. Es una medida del desarrollo de habilidades, promovida por los empleadores, que pretende el enriquecimiento del capital humano. En tal sentido, tratar de indagar y obtener resultados sobre la capacitación que reciben los asalariados en esta dimensión de ingresos suficientes y productividad tiene su importancia sobre el trabajo decente; sin embargo, al capturar la información sobre capacitación desde la GEIH solo se puede entrever si los asalariados han recibido algún tipo de capacitación, pero se desconocen el contenido, la duración y la calidad de la misma.

Según los resultados y según las limitaciones de la información, la tasa de asalariados que reciben capacitación en el AMVA, incluso en el contexto departamental es irrisoria, por no decir que nula, pues en ningún caso se llega al $1 \%$. Conviene advertir que para el cálculo de este indicador se consideraron los ocupados asalariados que manifestaron no haber trabajado las horas que normalmente laboran debido a que estaban en capacitación.

Gráfico 8. Tasa de asalariados que han recibido capacitación reciente

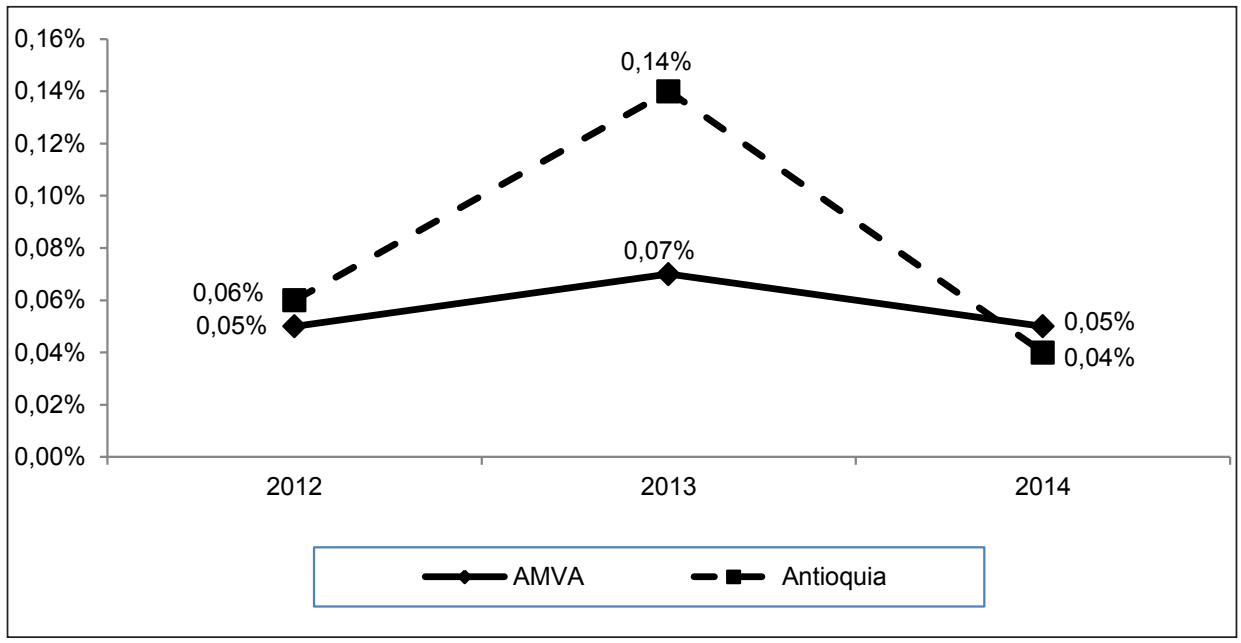

Fuente: elaboración propia con base en DANE-GEIH

Vale la pena sugerir la posibilidad de realizar una serie de estudios más detallados y con un levantamiento de información más directo y amplio con el cual se pueda 
validar si en efecto la tasa de capacitación es tan baja, así como también se puedan entender otras cosas, como: ¿qué tipo de capacitación se recibe? ¿Cuáles son los contenidos o las temáticas de las capacitaciones? ¿Cuál es la duración? y ¿̇cómo califican la calidad y la pertinencia de las capacitaciones?

\subsection{Tasa de ocupados en tiempo de trabajo excesivo}

Este indicador busca identificar los excesos en el trabajo, medidos por el mayor tiempo que se dedica a él, lo cual puede tener incidencia sobre los trabajadores desde diversos ámbitos: salud, tiempo familiar, relaciones sociales, descanso, recreación, etc. El indicador muestra el porcentaje de los ocupados que laboran en la semana más de las 48 horas legales. Para el AMVA el indicador permanece casi constante en el período analizado (31 \%), mientras que en el Departamento el indicador disminuyó de 35 \% a 32,1 \%. De acuerdo con Pineda (2013) la vida urbana en las principales ciudades lleva a los trabajadores a jornadas excesivas, y según los cálculos realizados para Bogotá más de la mitad de los trabajadores incurría en estos excesos: en 2012 el 61,4 \% de los trabajadores capitalinos laboraba más de lo permitido, mientras que en las grandes ciudades el porcentaje era el 63,9 \% y en el resto del país, 48,4\%. Si se compara al AMVA con estos resultados nacionales, se puede decir que corresponde a un resultado inferior a ellos, aunque permanece estable, lo que indica que hay posibilidades de establecer acuerdos, campañas y sensibilización en tal sentido, con el fin de mejorar el indicador.

Gráfico 9. Tasa de ocupados en tiempos de trabajo excesivo

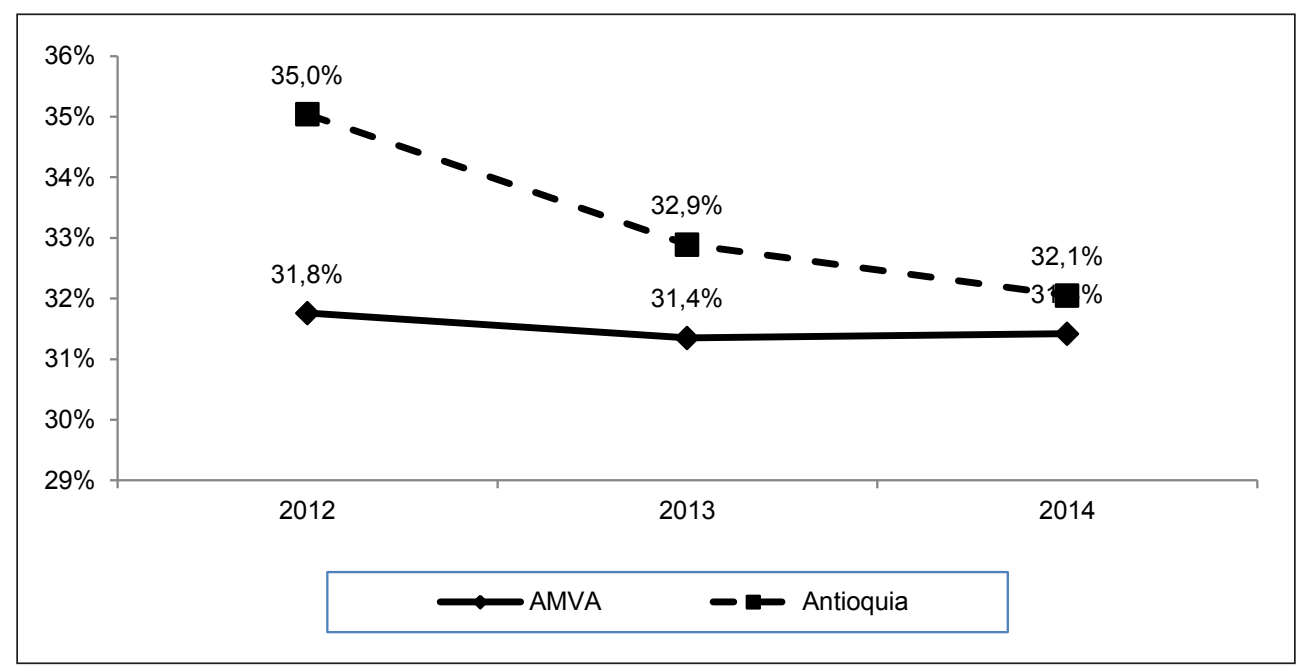

Fuente: elaboración propia con base en DANE-GEIH 
Al revisar los resultados del indicador por sexo se evidencia que en el AMVA los hombres registran una tasa mayor que las mujeres; aunque mientras los hombres registran un promedio de $37 \%$ para los tres años, las mujeres registran una tasa de $25 \%$.

Tabla 6. Tasa de ocupados en tiempo de trabajo excesivo según sexo

\begin{tabular}{|c|c|c|c|c|c|c|}
\hline \multirow{2}{*}{ Año } & \multicolumn{2}{|c|}{2012} & \multicolumn{2}{c|}{2013} & \multicolumn{2}{c|}{2014} \\
\cline { 2 - 7 } & n & n & n & n & i \\
\hline AMVA & $37,54 \%$ & $24,95 \%$ & $37,76 \%$ & $23,78 \%$ & $36,91 \%$ & $24,98 \%$ \\
\hline Antioquia & $37,13 \%$ & $35,90 \%$ & $38,82 \%$ & $24,53 \%$ & $38,06 \%$ & $23,61 \%$ \\
\hline
\end{tabular}

Fuente: elaboración propia con base en DANE-GEIH

\subsection{Ocupados por horas de trabajo a la semana}

Este indicador muestra la participación porcentual de los ocupados según el rango de horas trabajadas a la semana; en otras palabras, es el indicador anterior pero con una desagregación por rangos de horas inferiores a 48 que es el límite en Colombia. Los resultados dejan ver que cerca de un $70 \%$ de los ocupados trabajan hasta 48 horas, de los cuales un 21,5\% trabaja menos de 40 horas, $10 \%$ trabaja entre 40 y 47 horas, mientras que $37 \%$ trabaja 48 horas, es decir, están en el umbral. De acuerdo con Pineda (2013) este indicador proporciona información indirecta sobre el tiempo que los trabajadores pueden dedicar a actividades diferentes del trabajo, como descanso, vida familiar, trabajo doméstico, etc.

Gráfico 10. Distribución porcentual de los ocupados según jornada de trabajo

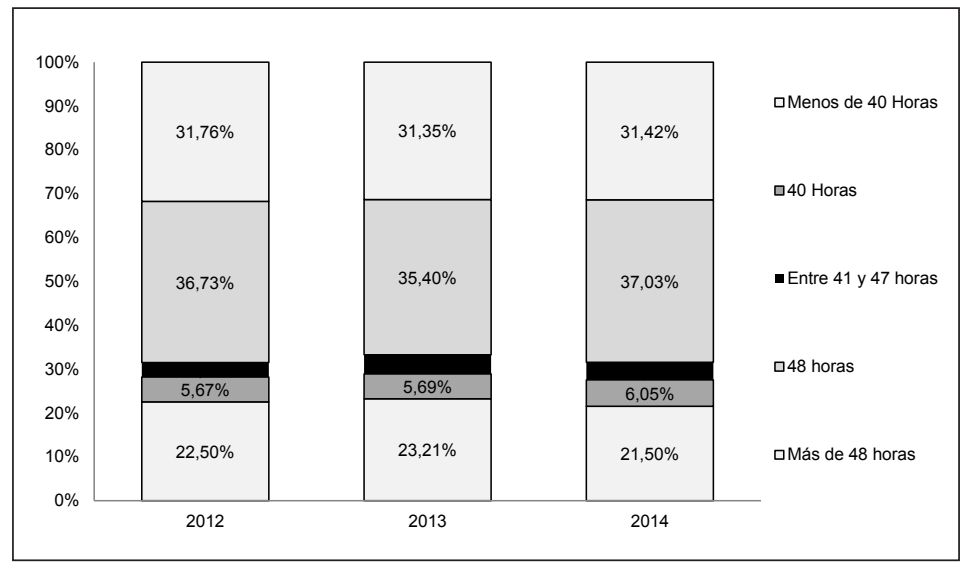

Fuente: elaboración propia con base en DANE-GEIH 


\subsection{Tasa de subempleo objetivo}

La medición del subempleo permite aproximarse y empezar a entender los niveles de insatisfacción que manifiestan los trabajadores sobre sus empleos, básicamente inscrito en tres categorías: ingresos, competencias y horas. No obstante, dos trabajadores pueden manifestar la misma insatisfacción pero pueden diferenciarse en que uno no ha hecho gestiones para cambiar de empleo, mientras que el otro sí. Esta situación es la que la explica la clasificación entre subempleo objetivo y subjetivo, respetivamente.

Gráfico 11. Tasa de subempleo objetivo

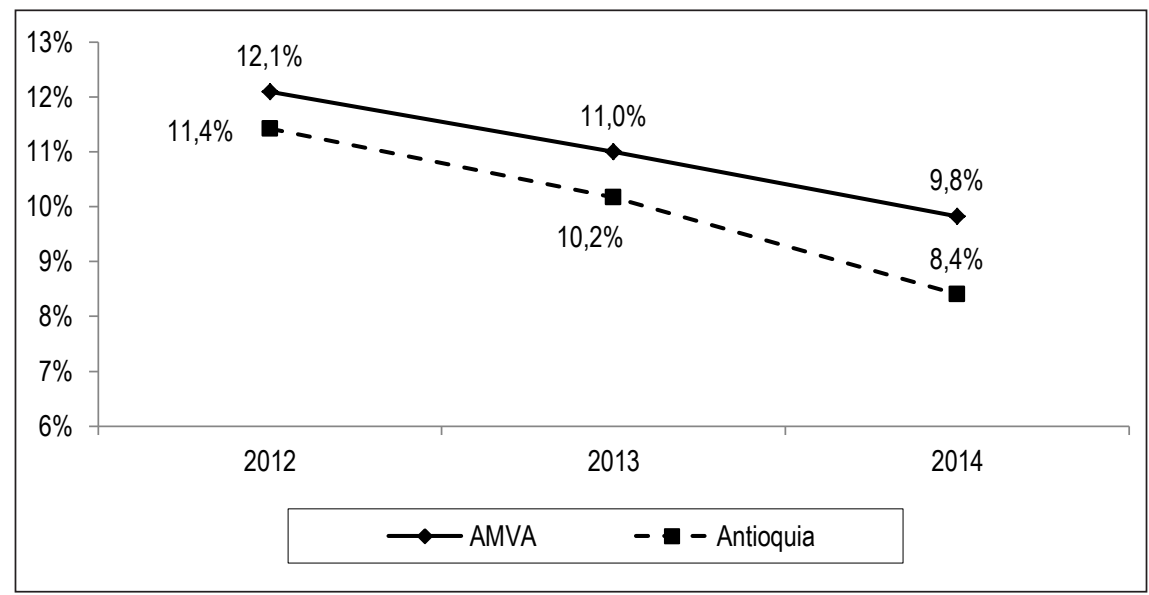

Fuente: elaboración propia con base en DANE-GEIH

La tendencia que refleja este indicador muestra que cada vez hay menos personas que se encuentran insatisfechas en su trabajo y que cada vez hacen menos gestiones para cambiar de empleo. Al revisar los resultados de los subempleados por insuficiencia de horas, es decir, aquellos que consideran que trabajan menos y podrían aumentar su tiempo en el trabajo, se aprecia que son la menor tasa dentro de los demás tipos de subempleo y pasó de 5,43 \% en 2012 a 4,19 \% en 2014.

Tabla 7. Tasa de subempleo objetivo según tipo

\begin{tabular}{lccc}
\hline \multicolumn{1}{r}{ Tipos de subempleo } & 2012 & 2013 & 2014 \\
Ingresos & $10,12 \%$ & $8,64 \%$ & $7,96 \%$ \\
Insuficiencia de horas & $5,43 \%$ & $5,37 \%$ & $4,19 \%$ \\
Competencias & $7,39 \%$ & $6,08 \%$ & $5,81 \%$ \\
\hline
\end{tabular}

Fuente: elaboración propia con base en DANE-GEIH 
Se debe llamar la atención sobre los subempleados por competencias, los cuales pueden ser un reflejo de los desajustes que pueda tener el mercado laboral en cuanto a la asignación de la mano de obra. Si bien dicha tasa no hace parte de este estudio, sí vale la pena hacer una mención al respecto.

\subsection{Tasa de subempleo subjetivo}

Este indicador refleja el nivel de insatisfacción laboral pero corresponde a un grupo de ocupados que no ha realizado gestiones para cambiar de empleo. La tendencia que refleja este indicador, tanto para el AMVA, como para Antioquia, es decreciente, ya que pasa de $31,8 \%$ en 2012 a 25,9 \% en 2014 para el caso del AMVA.

Gráfico 12. Tasa de subempleo subjetivo

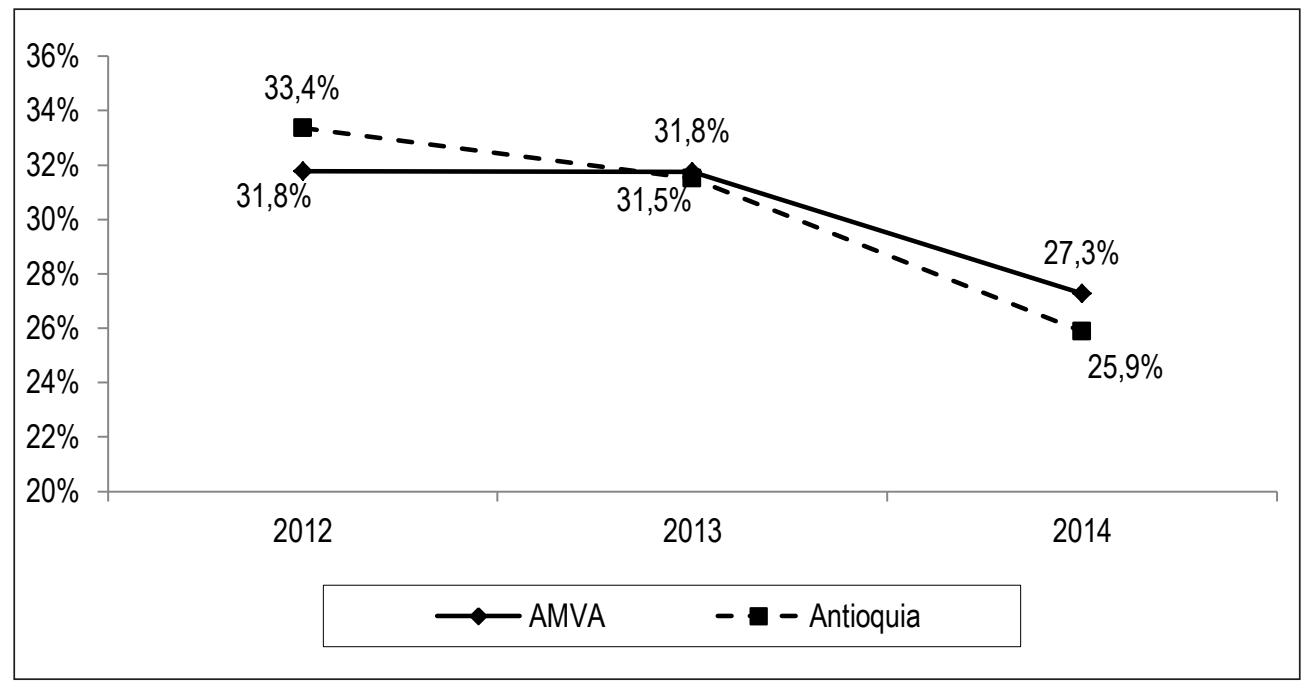

Fuente: elaboración propia con base en DANE-GEIH.

Al desagregar por tipo, la insuficiencia por horas es la que menos ha disminuido, y la diferencia con respecto al subempleo por competencias pasó de 6 puntos a 2.

Tabla 8. Tasa de subempleo subjetivo según tipo

\begin{tabular}{lccc}
\hline \multicolumn{1}{r}{ Tipos de subempleo } & 2012 & 2013 & 2014 \\
Ingresos & $27,04 \%$ & $25,60 \%$ & $21,82 \%$ \\
Insuficiencia de horas & $12,23 \%$ & $13,79 \%$ & $11,24 \%$ \\
Competencias & $18,66 \%$ & $16,75 \%$ & $14,79 \%$ \\
\hline
\end{tabular}

Fuente: elaboración propia con base en DANE-GEIH 


\subsection{Tasa de tiempo de trabajo no remunerado frente al remunerado}

El propósito del indicador es mostrar las cargas de tiempo de trabajo entre aquellas actividades remuneradas y las que no lo son. La premisa sobre la cual se parte es que los trabajadores dedican parte de su tiempo a actividades no remuneradas en el hogar y que dicha carga impide aceptar otras demandas de trabajo remuneradas fuera del hogar, lo cual tiene incidencia en la productividad, en los ascensos laborales, en la salud, entre otros aspectos. Pineda (2013, p. 46) sugiere que a medida que exista un mayor proceso de modernización de las ciudades, entendido como una mayor comercialización de aquellas actividades que antes no se remuneraban por ser realizadas en los hogares pero que ahora se realizan en establecimientos de comercio, se puede explicar un descenso en el indicador. Dichas actividades pueden estar relacionadas con la venta de alimentos, lavado de ropa, lavado de autos, belleza y cosméticos, entre otros.

Según los resultados, en el AMVA se aprecia una alta tasa de tiempo no remunerado frente al remunerado; por ejemplo, en 2014 el 64 \% del tiempo de los trabajadores fue dedicado a actividades no remuneradas, y si bien ha disminuido de niveles de $70 \%$ y $78 \%$, todavía se considera un nivel alto. Estos resultados pueden ser el reflejo de actividades desarrolladas en el hogar como cuidado de ancianos, preparación de alimentos, limpieza del hogar, entre otras; por ello es que resulta importante hacer un análisis y un seguimiento por sexo para comprobar conocimientos previos o fenómenos que se presentan en los hogares.

Gráfico 13. Tasa de tiempo de trabajo no remunerado frente al remunerado

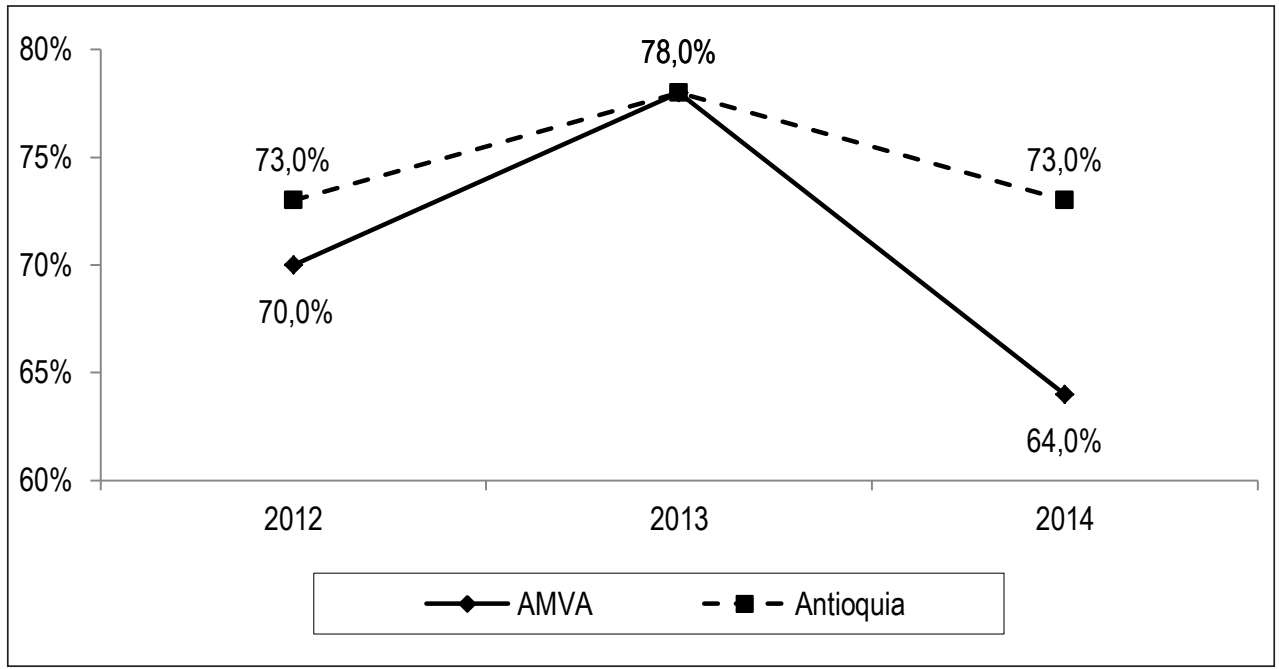

Fuente: elaboración propia con base en DANE-GEIH 
Los resultados por sexo reflejan un significativo desbalance que afecta más a las mujeres. Estos datos deben ser interpretados a la luz de la política de equidad de género y se espera que contribuyan en la definición de mejores metas para lograr superar barreras e inequidades. En 2014 los hombres dedicaron el 22 \% del tiempo a actividades no remuneradas, mientras que las mujeres dedicaron el $124 \% 3$.

Tabla 9. Tasa de tiempo no remunerado frente al remunerado

\begin{tabular}{|c|c|c|c|c|c|c|}
\hline \multirow[b]{2}{*}{ Año } & \multicolumn{2}{|c|}{2012} & \multicolumn{2}{|c|}{2013} & \multicolumn{2}{|c|}{2014} \\
\hline & & & & & & \\
\hline AMVA & $23,00 \%$ & $137,00 \%$ & $26,00 \%$ & $153,00 \%$ & $22,00 \%$ & $124,00 \%$ \\
\hline Antioquia & $22,00 \%$ & $166,00 \%$ & $24,00 \%$ & $172,00 \%$ & $23,00 \%$ & $160,00 \%$ \\
\hline
\end{tabular}

Fuente: elaboración propia con base en DANE-GEIH

De acuerdo con planteamientos de la OIT sobre este tema, un indicador alto puede significar dificultades para conciliar la relación trabajo-familia, lo que podría conducir a la aparición de conflictos que lesionan una u otra relación. En este orden de ideas este es un indicador que invita a pensar en un equilibrio en dicha relación trabajo-familia, y sería fundamental que las autoridades locales, los empresarios y las organizaciones comprendieran lo que hay detrás de este indicador.

\section{CONCLUSIONES Y RECOMENDACIONES}

Según estos resultados que han sido calculados desde el concepto de trabajo decente de la OIT, se debe aclarar que por recomendación del mismo organismo internacional, no es prudente hacer agregación de los indicadores y, en cambio, se aconseja un análisis detallado de los mismo, salvo que algunos se complementen, como la tasa de trabajadores pobres y la tasa de asalariados con bajos ingresos. En tal sentido, se evidencia que en el AMVA disminuye la tasa de trabajadores pobres, la cual pasó de 18,3 \% a 15,5\%, lo que significa avances dentro de la idea de lograr un trabajo decente, dado que es posible que algunos hogares hayan superado la línea de pobreza. Entretanto, la tasa de asalariados con bajos ingresos pasa del $15 \%$ al $14 \%$.

3 La interpretación de este indicador muestra que las mujeres dedicaron el 124 \% de su tiempo a actividades no remuneradas, sobre su tiempo remunerado. Por ello es que el resultado puede superar el ciento por ciento. 
Según estas tendencias es aconsejable que los municipios del AMVA definan unas metas a partir de estos resultados, con el propósito de obligarse al diseño de programas que conduzcan a reducir situaciones de pobreza entre los trabajadores y puedan empezar a incorporar una política local de empleo de la mano de los empleadores y de los trabajadores.

Una de las ideas que más fuerza ha tomado dentro los análisis de género es la discriminación laboral por sexo y especialmente la discriminación por ingresos en el mundo laboral, lo cual ha derivado en múltiples estudios a fin de encontrar evidencias que permitan corregir las fallas identificadas. En aras de contribuir a estas discusiones, los indicadores de ingresos calculados en este trabajo pueden servir como insumos para continuar los debates sobre el tema e invitan a explorar más sobre diversos aspectos; por ejemplo, según los ingresos medios por hora, se evidencia no solo una cierta brecha entre hombres y mujeres, sino también un aumento en dicha brecha. Dado que este estudio no indaga sobre posibles causas de estos cambios, valdría la pena señalar entonces que se identificó dicha situación con el ánimo de que se explore más y se puedan desarrollar otros trabajos que expliquen tal situación.

Uno de los resultados más bajos y que tiene incidencia directa sobre la productividad del trabajo es la capacitación. Los hallazgos medidos por la tasa de asalariados que hayan recibido capacitación reciente son nulos, prácticamente no existen capacitaciones en los puestos de trabajo, según la información que se captura desde la GEIH. Es probable que estos resultados sean producto de la manera como las empresas entienden la capacitación, pero, asimismo, es importante que se rescate la importancia que tiene en términos de productividad.

También se evidencia que la educación marca una brecha en términos de ingresos, la cual resulta significativa en el cálculo de los ingresos medios por hora entre quienes poseen educación y aquellos que no tienen educación; por lo tanto, estos resultados deben motivar serias y profundas reflexiones sobre la pertinente conexión que debe existir entre la política educativa local y los planes o programas de empleo.

Con respecto a los resultados sobre el tiempo de trabajo, se evidencia primero que un porcentaje importante de trabajadores (31 \%) labora más de 48 horas, lo que indica que esta situación no resulta favorable para el trabajo decente bajo el entendido de que dichas jornadas tienen incidencia sobre la salud, la recreación, la familia y el tiempo de descanso de las personas. Segundo, se evidencia que el indicador permanece estable durante el período analizado, por lo que se debe llamar la atención sobre dicha situación para animar a las autoridades locales para que inicien un proceso de pedagogía y sensibilización con empresarios a fin de lograr mejorar 
en el corto y mediano plazo este resultado. También conviene llamar la atención sobre el subempleo, primero, porque pocas veces se habla de él, y segundo, porque es posible que la reducción del desempleo y el aumento de la ocupación escondan ciertos niveles de insatisfacción de los trabajadores (subempleo).

Finalmente, el nivel de ocupación según horas a la semana para en el AMVA indica que el $30 \%$ de los ocupados trabaja más horas de las permitidas por Ley. Esto no es conveniente a la luz del trabajo decente, en virtud a que choca con los tiempos que el trabajador pudiese dedicar a otras actividades, incluso, a la misma recuperación física. Vale la pena seguir con la monitorización de este indicador con el fin de perseguir que la región le apueste a esquemas de trabajos más ajustados a los tiempos definidos en las normas laborales.

Es posible que el mercado laboral presente desarreglos y desajustes que todavía no han sido visibilizados, por ejemplo, el nivel de subempleo, el tiempo de trabajo excesivo -mencionado ante- y el tiempo de trabajo no remunerado sobre el remunerado, el cual merece una atención especial, pues se pudo identificar que los trabajadores dedican más de la mitad de su tiempo (entre un 60 \% y 70 \%) a actividades no remuneradas, lo cual no sería grave si dichas actividades estuvieran asociadas con el fortalecimiento de la fuerza de trabajo y mejoras en el capital humano; pero al revisar la desagregación por sexo, llama la atención la significativa distancia que hay entre hombre y mujeres, ya que son ellas las que dedican más del ciento por ciento del tiempo a actividades no remuneradas frente a actividades remuneradas. Esta situación invita a pensar que es posible que las mujeres dediquen buena parte de su tiempo a actividades del hogar lo que podría marcar una clara tendencia discriminatoria sobre las actividades realizadas allí. Convendría hacer un seguimiento a este indicador, al tiempo que serán bienvenidos los estudios que ayuden a esclarecer esta situación.

En síntesis, todos estos resultados son, en principio, una línea de base para la región, pero algunos ya reflejan una preocupación que amerita una intervención por parte de los actores involucrados en estos temas: autoridades locales, empleadores y trabajadores. Se espera que estos resultados contribuyan en la definición de programas o políticas que vengan en pro de mejorar las condiciones laborales de las personas, la productividad de las empresas y el nivel de bienestar social de todos.

\section{BIBLIOGRAFÍA}

Betancur, S.; Urán, O. A. y Stienen, A. (2001). Globalización: cadenas productivas y redes de acción colectiva: reconfiguración territorial y nuevas formas de pobreza en Medellìn y el Valle de Aburrá. Medellín: Instituto Popular de Capacitación -IPC-, 383p 
Ingresos laborales y tiempos en el trabajo en Antioquia y el área metropolitana del Valle de Aburrá 2012-2014

CCMA -Cámara de Comercio de Medellín para Antioquia- (2015). Economía regional: persiste la fortaleza de Antioquia en un ambiente de marcada inestabilidad internacional. Revista Antioqueña de Economía y Desarrollo, 93p.

Coronel, J. (2015). Incremento del desempleo cada vez más cerca. El Mundo, p. 8.

Franco Restrepo, V. L. (2006). Poder regional y proyecto hegemónico. El caso de la ciudad metropolitana de Medellín y su entorno regional 1970-2000. Medellín: Instituto Popular de Capacitación (IPC), 486p.

Ghai, D. (2003). Trabajo decente. Concepto e indicadores. Revista Internacional del Trabajo. Vol. 22. ․․ 2. Organización Internacional del Trabajo, pp. 125-160.

López, H. (1997). Educación y mercado laboral políticas locales y nacionales de empleo y capacitación. Medellín: Cámara de Comercio de Medellín, 116p.

Lopez, H.; Lotero, J. y Arango, M. (1992). La problemática laboral en Antioquia. Comportamientos recientes y tendencias futuras. Medellín: L. Vieco, 187p.

OIT -Organización Internacional del Trabajo- (1999). Memoria del Director General: Trabajo Decente. 87. ${ }^{a}$ reunión. Conferencia Internacional del Trabajo. Ginebra: OIT, $111 \mathrm{p}$.

OIT -Organización internacional del Trabajo - (2001). Memoría del Director General. Reducir el déficit de trabajo decente: un desafío global. Conferencia internacional del trabajo. 89. ${ }^{a}$ reunión (Primera ed.). Ginebra: OIT, 92p.

OIT -Organización internacional del Trabajo- (2013). Decent Work Indicators. Guidelines for producers and users of statistical and legal framework indicators. OIT, 254p.

OIT -Organización internacional del Trabajo- (2013a). Informe mundial de salarios 2012-2013. Los salarios y el crecimiento equitativo. Ginebra: Oficina Internacional del Trabajo, 134p.

OIT -Organización internacional del Trabajo- (2015). El programa de trabajo decente. OIT.

OIT -Organización internacional del Trabajo- (2008). Medición del trabajo decente: documento de debate para la reunión tripartita de expertos sobre la medición del trabajo decente, Ginebra 8-10 de septiembre de 2008. Ginebra: OIT, 73p.

OCDE -Organización para la Cooperación y el Desarrollo Económico- (2016). Estudio de la OCDE sobre el mercado laboral y las políticas sociales: Colombia 2016. OCDE, 36p.

Pineda, J. (2013). El trabajo decente en Bogotá. Diagnóstico, análisis y perspectivas. Bogotá: Uniandes, 201p.

Proantioquia (2013). Proantioquia 2005-2012: Visiones, logros y retos. Medellín: Fundación Proantioquia, 316p.

Puig, F. J. (2011). Situación de la subcontratación en América Latina y perspectivas para su regulación. Ensayos laborales 20. Medellín: Escuela Nacional Sindical -ENS-, 115p.

Restrepo Santamaría, N. (2011). Empresariado antioqueño y sociedad, 1940-2004. Medellín: Universidad de Antioquia, 333p.

Somavia, J. (1999). Memoria del Director. Trabajo Decente. En: Conferencia Internacional del Trabajo. Reunión 87. ${ }^{\text {a Ginebra: OIT. }}$

Uribe, M. T. (2006). Poder político y región. En: M. Hermelin, Geografía de Antioquia. Medellín: Fondo Editorial Eafit. 281-287p.

Valencia, N. (2005). La negociación colectiva no es solo un derecho. Revista Cultura y Trabajo. N. ${ }^{\circ} 63$. 
ANEXO A

FICHA TÉCNICA DE LOS INDICADORES CALCULADOS PARA MEDIR LOS INGRESOS LABORALES Y TIEMPOS EN EL TRABAJO

\begin{tabular}{|l|l|}
\hline \multicolumn{2}{|c|}{ Ficha técnica del indicador tasa de trabajadores pobres } \\
\hline Definición & $\begin{array}{l}\text { Porcentaje de la población que si bien se encuentra ocupada, viven en la pobreza, } \\
\text { esto es, el ingreso familiar per cápita es inferior a la línea de pobreza según año } \\
\text { y territorio }\end{array}$ \\
\hline $\begin{array}{l}\text { Fórmula } \\
\text { de Cálculo }\end{array}$ & $\begin{array}{l}(\mathrm{POP} / \mathrm{PO})^{*} 100 \\
(\text { Población ocupada en condiciones de pobreza monetaria / Población ocupa- } \\
\text { da)*100 }\end{array}$ \\
\hline
\end{tabular}

\begin{tabular}{|l|l|}
\hline \multicolumn{2}{|c|}{ Ficha técnica tasa de asalariados con bajos ingresos } \\
\hline Definición & Relación porcentual de ocupados asalariados que trabajan por salarios bajos \\
\hline $\begin{array}{l}\text { Fórmula } \\
\text { de Cálculo }\end{array}$ & $\begin{array}{l}\text { (Número de asalariados pagados con menos de 2/3 de la mediana del salario por } \\
\text { hora /Asalariados totales) x } 100\end{array}$ \\
\hline
\end{tabular}

\begin{tabular}{|l|l|}
\hline \multicolumn{2}{|c|}{ Ficha técnica ingreso medio por hora } \\
\hline Definición & Ingreso laboral medio por hora \\
\hline $\begin{array}{l}\text { Fórmula de } \\
\text { Cálculo }\end{array}$ & ((Ingreso laboral mensual / Horas trabajadas a la semana*4) / PO) \\
\hline
\end{tabular}

\begin{tabular}{|l|l|}
\hline \multicolumn{2}{|c|}{ Ficha técnica salario promedio real } \\
\hline Definición & Ingreso laboral mensual promedio de asalariados a precios constantes de 2008 \\
\hline $\begin{array}{l}\text { Fórmula de } \\
\text { Cálculo }\end{array}$ & (Ingreso laboral mensual de asalariados / Promedio IPC mensual según año)*100 \\
\hline
\end{tabular}

\begin{tabular}{|l|l|}
\hline \multicolumn{2}{|c|}{ Ficha técnica salario promedio real } \\
\hline Definición & $\begin{array}{l}\text { Proporción de asalariados que han recibido capacitación. Es una medida del } \\
\text { desarrollo de habilidades promovido por los empleadores (enriquecimiento del } \\
\text { capital humano) }\end{array}$ \\
\hline $\begin{array}{l}\text { Fórmula de } \\
\text { Cálculo }\end{array}$ & $\begin{array}{l}\text { (POAC / POA })^{*} 100 \\
(\text { PO asalariada capacitadas recientemente / Población ocupada asalariada)*100 }\end{array}$ \\
\hline
\end{tabular}

\begin{tabular}{|l|l|}
\hline \multicolumn{2}{|c|}{ Ficha técnica tasa de ocupados en tiempo excesivo } \\
\hline Definición & Porcentaje de los ocupados que laboran en la semana más de las 48 horas legales \\
\hline $\begin{array}{l}\text { Fórmula de } \\
\text { Cálculo }\end{array}$ & $\begin{array}{l}\text { (POE / PO)*100 } \\
\text { (Población ocupada en jornadas de más de 48 horas semanales / Población } \\
\text { ocupada)*100 }\end{array}$ \\
\hline
\end{tabular}


Ingresos laborales y tiempos en el trabajo en Antioquia y el área metropolitana del Valle de Aburrá 2012-2014

\begin{tabular}{|l|l|}
\hline \multicolumn{2}{|c|}{ Ficha técnica ocupados por hora de trabajo a la semana } \\
\hline Definición & $\begin{array}{l}\text { Participación porcentual de los ocupados según rango de horas trabajadas a la } \\
\text { semana }\end{array}$ \\
\hline $\begin{array}{l}\text { Fórmula de } \\
\text { Cálculo }\end{array}$ & $\begin{array}{l}\text { (PO según horas de trabajo / PO)*100 } \\
\text { (Población ocupada según rango de horas de trabajo a la semana / Población } \\
\text { ocupada)*100 }\end{array}$ \\
\hline
\end{tabular}

\begin{tabular}{|l|l|}
\hline \multicolumn{2}{|c|}{ Ficha técnica de subempleo objetivo } \\
\hline Definición & $\begin{array}{l}\text { Relación porcentual entre el número de personas subempleadas y el de personas } \\
\text { que integran la fuerza laboral }\end{array}$ \\
\hline $\begin{array}{l}\text { Fórmula de } \\
\text { Cálculo }\end{array}$ & $\begin{array}{l}\text { (SO / PEA)*100 } \\
\text { Ocupados con al menos una de las características de subempleo objetivo / PEA }\end{array}$ \\
\hline
\end{tabular}

\begin{tabular}{|l|l|}
\hline \multicolumn{2}{|c|}{ Ficha técnica de subempleo subjetivo } \\
\hline Definición & $\begin{array}{l}\text { Relación porcentual entre el número de personas subempleadas y el de personas } \\
\text { que integran la fuerza laboral }\end{array}$ \\
\hline $\begin{array}{l}\text { Fórmula de } \\
\text { Cálculo }\end{array}$ & $\begin{array}{l}\text { (SS / PEA)*100 } \\
\text { (Ocupados con al menos una de las características de subempleo subjetivo / } \\
\text { Población económicamente activa)*100 }\end{array}$ \\
\hline
\end{tabular}

\begin{tabular}{|l|l|}
\hline \multicolumn{2}{|c|}{ Ficha técnica de tiempo de trabajo no remunerado frente al remunerado } \\
\hline Definición & $\begin{array}{l}\text { Razón del número de horas semanales destinadas a actividades no remuneradas } \\
\text { frente al número de horas semanales destinadas a trabajo remunerado }\end{array}$ \\
\hline $\begin{array}{l}\text { Fórmula de } \\
\text { Cálculo }\end{array}$ & $\begin{array}{l}\text { \# de horas de trabajo no remunerado semanales / \# de horas de trabajo remune- } \\
\text { rado semanales }\end{array}$ \\
\hline
\end{tabular}


